IZA DP No. 7235

Measurement of Environmentally Sensitive

Productivity Growth in Korean Industries

Yeimin Chung

Almas Heshmati

February 2013 


\title{
Measurement of Environmentally Sensitive Productivity Growth in Korean Industries
}

\author{
Yeimin Chung \\ Korea University \\ Almas Heshmati \\ Sogang University \\ and IZA \\ Discussion Paper No. 7235 \\ February 2013 \\ IZA \\ P.O. Box 7240 \\ 53072 Bonn \\ Germany \\ Phone: +49-228-3894-0 \\ Fax: +49-228-3894-180 \\ E-mail: iza@iza.org
}

\begin{abstract}
Any opinions expressed here are those of the author(s) and not those of IZA. Research published in this series may include views on policy, but the institute itself takes no institutional policy positions. The IZA research network is committed to the IZA Guiding Principles of Research Integrity.

The Institute for the Study of Labor (IZA) in Bonn is a local and virtual international research center and a place of communication between science, politics and business. IZA is an independent nonprofit organization supported by Deutsche Post Foundation. The center is associated with the University of Bonn and offers a stimulating research environment through its international network, workshops and conferences, data service, project support, research visits and doctoral program. IZA engages in (i) original and internationally competitive research in all fields of labor economics, (ii) development of policy concepts, and (iii) dissemination of research results and concepts to the interested public.
\end{abstract}

IZA Discussion Papers often represent preliminary work and are circulated to encourage discussion. Citation of such a paper should account for its provisional character. A revised version may be available directly from the author. 


\begin{abstract}

\section{Measurement of Environmentally Sensitive Productivity Growth in Korean Industries}

This study measures productivity growth using the Metafrontier Malmquist-Luenberger productivity growth index (MML index) method and decomposes the index. The results are compared with those obtained from the conventional Malmquist-Luenberger (ML) productivity growth index. MML has two advantages compared with the ML index. The former is able to consider undesirable output as a by-product of production which accounts for producer group heterogeneities. As a result, it enables separation and estimation of changes in the technological gap between regional and global frontier technologies. The proposed index is employed to measure productivity growth and decompose its components in 14 Korean industrial sectors during the period between 1981 and 2007. For the purpose of detailed analysis of policy effects, the study period was divided into three decades. The results show that technology innovation can be regarded as a more important factor of productivity growth, rather than efficiency change. The chemical and Petrochemical, Machinery and Transport equipment industries are treated as global innovators in the whole period. However, the result differs according to decades. It is found that the groups with higher energy efficient technology and profitability obtain a higher productivity growth rate in comparison with their low energy efficient technology industry counterparts. Policy implications of the empirical results are discussed.
\end{abstract}

JEL Classification: D24, C61, O31, O44

Keywords: $\quad \mathrm{CO}_{2}$ emission, undesirable output, DEA, Malmquist-Luenberger productivity $(\mathrm{ML})$ index, Metafrontier Malmquist-Luenberger productivity (MML) index, productivity change

Corresponding author:

Almas Heshmati

Department of Economics

Sogang University

Sinsoo-dong \#1, Mapo-gu

Seoul 121-742

Korea

E-mail: almas.heshmati@gmail.com 


\section{Introduction}

This study tested the effect of $\mathrm{CO}_{2}$ emission on production outcome by examining whether and by how much productivity of industries in Korea changes when they are faced with the regulation pressure of reducing the $\mathrm{CO}_{2}$ emission level. Also, we attempted to find evidence of tied environment policy effects on productivity growth at the industry level. Recently, Korea has employed several policies concerning the environment, especially air pollution. Most of these policies have been carried out after adoption of the Kyoto protocol in 1997. Following the Kyoto protocol, thirtyeight developed countries that have assumed duty of transition were obliged to cut down their emission of greenhouse gases. ${ }^{1}$ Since Korea was not classified as a developed country then, the country was given extra adjustment time to prepare for being a country with duty of transition. However, Korea will get obligations of transition to a cleaner production structure sooner, due to the country's high emission level. $^{2}$

In this situation, we hope to be able to analyze closely how well Korea is prepared to follow the Kyoto protocol by analyzing data from 1981 to 2007. The target of environmental policy is management of environmentally harmful outputs. Most harmful outputs are produced in the form of by-products, not as primary products. Therefore, output can be divided into desirable and undesirable outputs. Despite the fact that firms do not have any intention to produce harmful undesirable outputs, government should control the amount of undesirable output in order to achieve the goal of environmental policy. Under such conditions, firms and industries are obliged to adjust their environmental policies and their economic circumstances through even decreasing the desirable output to reduce the undesirable output or to induce necessary changes in their production processes.

Since no firm wants to decrease their desirable output on a free basis, most firms and industries are forced to change their production processes by taking advantage of technical progress. For this reason, both firms and industries are faced with productivity changes based on internal and external technological levels. This study contributes to the existing literature by employing a methodology that is superior to the commonly used methodology in the area of environment by accounting for heterogeneities in behavior by industrial sector. The new approach is applied to data from a newly industrial economy, Korea, which is intending to adopt the Kyoto protocol.

It should be noted that, of more importance in this context is the understanding of the relationship between productivity and $\mathrm{CO}_{2}$ emission. Based on this relation, policies related to environmental aspects are considered and carried out in practice. However, questions are asked about whether the introduced policies and measures are relevant and sufficient to counterbalance economic loss generated from $\mathrm{CO}_{2}$ emissions mitigation.

On behalf of considering this problem in all its dimensions, in this study, we attempt to find stronger evidence that $\mathrm{CO}_{2}$ emission as undesirable output becomes a production environmental constraint ${ }^{3}$ in the expansion of production activities.

\footnotetext{
${ }^{1}$ Greenhouse gases consist of six components: $\mathrm{CO}_{2}, \mathrm{CH}_{4}, \mathrm{~N}_{2} \mathrm{O}, \mathrm{PHC}, \mathrm{HFC}$ and $\mathrm{SF}_{6}$.

2 While we study, the 18th UNFCCC held for modifying what was promised by the developed countries at Kyoto protocol set in 1997.

3 Yang et al. (2011) found a positive relationship between pollution abatement fees and R\&D expenditures, but there is no evidence to support an R\&D-inducement effect brought about by PACE.
} 
According to Kim et al. (2010), most studies related with the environment insist on the positive relationship between $\mathrm{CO}_{2}$ emission and economic activity. Also, through this process, policy makers can support firms by suggesting a set of effective policies ${ }^{4}$ to enhance of productivity levels of individual firms directly and that of aggregate industries indirectly. The Metafrontier Malmquist-Luenberger productivity index (MML index) is used to shed light on these issues which embody the contribution of this paper to the literature.

The rest of this study is organized as follows. In Section 2, we introduce the background to the MML index followed by a review of the literature in Section 3. The MML methodology and empirical models are outlined in Section 4. Section 5 presents the empirical results based on Korea industry level data. The final Section 6 provides a summary and policy recommendations.

\section{Background to the MML index ${ }^{5}$}

For measurement of undesirable output, we used the MML index, a non-parametric measurement method. The MML index is the expanded and developed form of the Malmquist index ( $M$ index) which uses data envelope analysis (DEA) for its computation. By following the general character of $\mathrm{DEA}^{6}$, the $\mathrm{M}$ index has many advantages in measuring productivity growth index. It is widely applicable and does not require any assumption of functional form for the production function prior to estimation, as well as assumption about distribution of any error term. Using the above characteristics, Farrell (1957) empirically obtained the inefficiency of sample of firms using linear programming. Farrell suggested many key concepts ${ }^{7}$ of DEA that became basic assumptions to the measurement process. Even though Farrell built up DEA more concretely, this methodology has been questioned by economics and econometrics disciplines due to the disadvantage of not estimating the elasticity of input variables, as well as not considering characteristics of production and the statistical random error term. These disadvantages made DEA to be regarded as a nonstandard econometric methodology and as a frequently employed benchmark alternative approach of computing productivity growth.

In order to overcome the disadvantage as a non-parametric method, Aigner and Chu (1968) suggested deterministic parametric frontier analysis which continued to develop until the stochastic frontier analysis (SFA) method was introduced simultaneously by Aigner, Lovell and Schmidt (1977) and Meeusen and van den Broeck (1977). SFA has become the most useful method to parametrically analyze the production and cost efficiency of production units. After Banker (1993) proved that

\footnotetext{
It supports that regulation on undesirable output could be one of constraints of normal activity of an economy.

${ }^{4}$ Their argument is stood by the theory of porter which claimed that R\&D induced by any regulations makes it possible to enhance their productivity in long-run even if using new technologies will imply that firms or industries face a higher expenditure than before.

${ }^{5}$ This section has benefitted much from Coelli, T.J., Rao, D.S.P., O’Donnell, C.J., Battese, G.E., 2005. Introduction to efficiency and productivity analysis, $2^{\text {nd }}$ edition, Springer, Heidelberg.

${ }^{6}$ While calculating the productivity index, DEA does not need any specific production function, such as Cobb-Douglas or log-log production functional form. DEA only used given data for analyzing the relationship between output and input and as a non-parametric estimation method.

${ }^{7}$ Such as production probability set (PPS), convexity, disposability, allocation efficiency, technical efficiency, and so on.
} 
DEA also has statistical properties, Malmquist index ${ }^{8}$ was utilized and developed continually. Through adoption of linear programming ${ }^{9}$ based on directional distance function, Malmquist-Luenberger index (ML index), Sequential MalmquistLuenberger index (SML index) and MML index have been developed and applied frequently by many researchers to diverse areas. For the matter of sensitivity of the results to measurement method, the methods are often employed in concurrence and compared.

\section{Literature Review}

There are many studies analyzing the impact or causality effects between productivity growth and $\mathrm{CO}_{2}$ emission. Thus, we will first describe the literature that studies about such relationships and then review the methodology used in this study.

Several studies have tried to find evidence of causality between productivity growth and $\mathrm{CO}_{2}$ emission using different methodologies such as parametric and nonparametric approaches. Among parametric methods, one methodology that is most widely used is time series analysis. Most previous studies using time series models were tended to assume simple linearity with lag structure in the relationship between GDP and $\mathrm{CO}_{2}$ representatively. Under a simple linearity assumption, the Grangercausality test was examined to capture possible causality and its direction between the two indicators. However, there was evidence of divergence in the conclusion on the matter of direction of causality.

There have been a number of trials to analyze the causality between productivity growth and $\mathrm{CO}_{2}$ emission. Hsieh (1991) and Brock and LeBaron (1996) insisted that the assumption of non-linear relationship is more appropriate than the assumption of linearity between the two indicators due to the cyclical components of the economies. Accepting the nonlinearity assumption has led to introduction of many alternative methodologies which were further developed for analyzing the indicators' causal relationship, for example, the smooth transition autoregressive model (STAR) that was developed by Luukkonen et al. (1988) and the Threshold Vector Error Correction Model developed by Hansen and Seo (2002). In these models, non-linearity is introduced in both the explanatory variables and their associated time variant parameters.

Thus, most recent studies using parametric methods suggested that economic growth or productivity growth and $\mathrm{CO}_{2}$ emission have mutual or two ways causality relationship. Therefore, under this conclusion, it is justified that we could assume (i) non-linearity and (ii) mutual causality between the two factors when using the nonparametric method here. In the present study, we employed the MML index in order to consider the undesirable output and thereby decompose the rate of productivity growth. In order to use and perform analysis by the MML index, we first need to examine previous studies employing the DEA based ML index.

In most previous studies, the ML index and directional distance function were used for analyzing productivity growth with a concept of undesirable output. Chung et al. (1997) employed undesirable output as a by-product when a unit produced

\footnotetext{
${ }^{8}$ Douglas W. Caves, Laurits R. Christensen and Walter E. Diewert introduced the Malmquist index in the 1982 with the title "Multilateral Comparisons of Output, Input and Productivity Using Superlative Index Numbers”.

${ }^{9}$ Linear programming (LP) was used to decide a way to get the best outcome, such as maximum profit or lowest cost, in a given mathematical model for some list of requirements that represented linear relationships.
} 
desirable output and analyzed productivity growth at the micro-level. They announced that technical change is a prior source of productivity growth in Swedish paper and pulp mills for the period of 1986-1990. In another study, Fare et al. (2001) adopted the ML index methodology and used micro panel data to analyze the relationship between market output and pollution abatement cost in 1974-1986. Following the study of Fare et al. (2001), the ML index has been used extensively as a standard best practice methodology for estimating productivity growth in wide areas of performance related research.

In addition, Weber and Domazlicky (2001) applied a similar methodology as with Fare et al. (2001) in order to include toxic release in the productivity analysis of the US manufacturing sector in 1988-1994. Pasurka (2006) used the ML index in order to decompose the productivity growth of US coal-fired electric power plants. In the case of Japan, Nakano and Managi (2008) measured productivity in the steam power generation sector to examine the effects of industrial reforms on the productivity of generator plants from 1978 to 2003. Sueyoshi and Goto (2010) proposed a new use of DEA to measure the operational, environmental and unified efficiency measures of US coal-fired power plants.

Kumar (2006) also employed the ML index to analyze the environmentally sensitive productivity growth of 41 countries for the period between 1973 and 1992 . In his study, Kumar found that the productivity growth of Annex-I countries are higher than that of non-Annex-I countries ${ }^{10}$, and that technical change was the main contributor to productivity growth.

In a recent study, Oh and Heshmati (2010) proposed an index for measuring environmentally sensitive productivity growth which appropriately considers the characters of technical change in production. In order to incorporate this aspect in developing the index, a directional distance function and the concept of successive sequential production possibility set were combined. With this combination, the conventionally used Malmquist-Luenberger productivity index was modified to give the Sequential Malmquist-Luenberger (SML) productivity index. This index was employed to measure environmentally sensitive productivity growth and its decomposed components of 26 OECD countries for the period of 1970-2003.

It should be mentioned that, in several of the abovementioned studies in which the ML index was used have a weakness in terms of individual heterogeneity, where individuals are either highly aggregated industrial sectors or countries. To account for the heterogeneity of groups, each group has a different situation with regard to production technology and productivity growth. Therefore, results estimated by the ML index should be biased in representing the actual productivity growth of individual groups. Oh (2010a) attempted to solve the heterogeneity problem and suggested the Metafrontier ML index (MML index) as a preferable method to estimate productivity growth. Oh presented an alternative environmentally sensitive productivity growth index to incorporate group heterogeneities into the conventional Malmquist-Luenberger productivity growth index. The proposed approach allows for the calculation of both efficiency and technical changes for economic agents operating under different technologies. Moreover, it also enables the computation of changes in the technological gap between regional and global frontier technologies. The proposed index is employed to measure productivity growth and its decomposed components in 46 countries observed between 1993 and 2003. The main finding

\footnotetext{
10 Annex-I countries tend to represent developed countries and non-Annex-I indicates developing countries.
} 
indicates that Europe has taken the lead in the world frontier technology and that Asia has attempted to catch up by moving towards the frontier technology.

It is worth to mention that the MML index is a combination of two concepts. One is the conventional ML index, and another is the concept of Metafrontier. The Metafrontier is the envelope of the conceived production frontiers introduced by Battese and Rao (2002) and further described in Battese et al. (2004). Battese and Rao (2002) tried to solve for the incomparability of performances of various groups through using the concept of Metafrontier or global frontier which is a composite of different sub-frontiers, which are labeled regional frontiers here, representing adoption of different technologies in the same industrial sector.

Although a large number of studies have been performed using the ML index, there are very few studies that have utilized the concept of the MML index. Kumar (2006), Oh and Heshmati (2010), Oh (2010b) and Chiu et al. (2012) are representative studies on productivity growth related environmental issue employing ML, SML and MML indices. As we mentioned, Oh (2010b) considered incorporation of ex ante group heterogeneities, thus utilized the MML index to measure environmentally sensitive productivity growth at the macro-level. The result showed that European countries are good at innovating and Asian countries are good at imitating and catching up with the world frontier technology.

\section{Methodology and Model}

Prior to modeling the MML index, we will discuss the underlying assumptions and the issues of directional distance function which the index computation is based on. Subsequently, we will construct the index model and decompose the index into its each underlying components part with specific economic interpretation.

\subsection{The fundamental assumptions}

This section deals with the fundamental assumptions required for defining the ML and MML indices. The study of Färe et al. (2005) and Oh (2010b) are based on four basic assumptions that are followed here. They suggested that the production possibility set (PPS) for decision making units (DMUs) is represented by the output set $P(x)$, where DMUs produce $\mathrm{M}$ desirable outputs, $Y \in R_{+}^{M}$, and $\mathrm{J}$ undesirable byproducts, $b \in R_{+}^{j}{ }^{11}$. The output set consists of desirable and undesirable output vector $(\mathbf{y}, \mathbf{b})$ that is jointly produced from $\mathrm{N}$ inputs which is represented by the input vector, $x \in R_{+}^{N}$. The PPS is then expressed as follows:

$$
\begin{gathered}
P(\boldsymbol{x})=\{(\boldsymbol{y}, \boldsymbol{b}) \mid \boldsymbol{x} \text { can produce }(\boldsymbol{y}, \boldsymbol{b})\} \\
\text { if } \boldsymbol{x}^{\prime} \geq \boldsymbol{x} \text { then } P\left(\boldsymbol{x}^{\prime}\right) \supseteq P(\boldsymbol{x})
\end{gathered}
$$

Equation (1) represents the production technology mathematically. In order to explain more characteristics of equation (1), it is necessary to consider the undesirable outputs. Therefore, we employed some assumptions as below:

\footnotetext{
11 Following the study of Chung, Y.H., Färe, R. (1995), if a desirable output is produced in a positive amount some undesirable output must also be produced. Thus, undesirable output is bound as the positive set.
} 


$$
\begin{gathered}
\text { if }(\boldsymbol{x}, \boldsymbol{y}, \boldsymbol{b}) \in P \text { and } \boldsymbol{b}=0 \text {, then } \boldsymbol{y}=0 \\
\text { if }(\boldsymbol{y}, \boldsymbol{b}) \in P(\boldsymbol{x}) \text { and } 0 \leq \theta \leq 1 \text {, then }(\theta \boldsymbol{y}, \theta \boldsymbol{b}) \in P(\boldsymbol{x}) \\
\text { if }(\boldsymbol{x}, \boldsymbol{y}, \boldsymbol{b}) \in P \text { and } \boldsymbol{y}^{\prime} \leq \boldsymbol{y} \text {, then }\left(\boldsymbol{x}, \boldsymbol{y}^{\prime}, \boldsymbol{b}\right) \in P \\
\text { if }(\boldsymbol{y}, \boldsymbol{b}) \in \mathrm{P}(\boldsymbol{x}) \text { and } \boldsymbol{y}^{\prime} \leq \boldsymbol{y} \text { then }\left(\boldsymbol{y}^{\prime}, \boldsymbol{b}\right) \in P(\boldsymbol{x})
\end{gathered}
$$

Jointness and disposability are among important production characteristics. Equation (3) expresses the characteristic called null-jointness. It means that desirable output cannot be produced independently from undesirable output. Equation (4) shows the characteristic of weak disposability. This condition allows for the reduction of the undesirable outputs only when it occurs by simultaneous reduction of the desirable outputs and with the same proportional contraction. Equation (5) indicates that the desirable outputs can be freely disposed. Thus, the desirable output may be decreased while simultaneously decreasing the undesirable outputs. The last assumption, equation (6), indicates that if an observed outputs vector is feasible, then any output vector smaller than that is also feasible. This also means that some of the desirable outputs can always be disposed without any cost incurred. Using the above assumptions, the production possibility frontier combination of desirable and undesirable output is expressed as in Figure 1. We assumed that A, B, C and D are observed as actual combined production points.

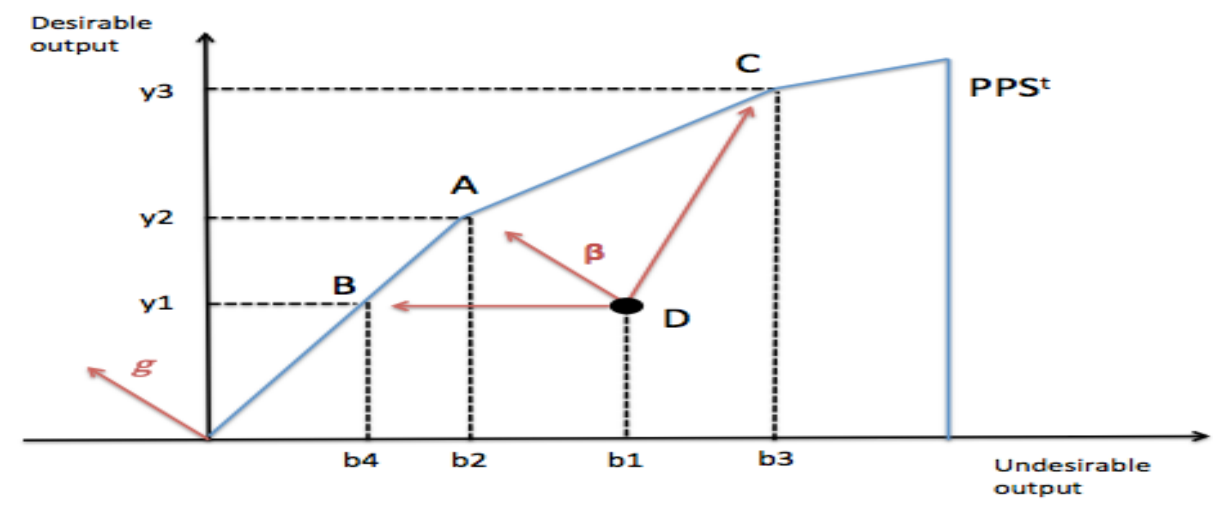

Figure 1. Production possibility set combining production of desirable and undesirable outputs. ${ }^{12}$

In Figure 1, if the initial output set $\mathrm{D}$, given as $\left(\mathrm{y}_{1}, \mathrm{~b}_{1}\right)$, is inefficient because it is placed at the interior of PPS, it means DMUs have to choose their optimal strategy to reach the frontier of PPS. Arcelus and Arocena (2005) indicated that DMU tends to take their circumstances into consideration while choosing the production level. In this situation, DMUs can move to points A, B and C. Because currently we discuss the way of simultaneous development of economy and environment, $\beta$ could be determined as the direction that increases the desirable output and decreases the undesirable output. Likewise, each DMU should move toward the frontier in order to achieve a higher level of efficiency, thus, $\beta$ could be defined as an inefficiency index.

\footnotetext{
12 According to the concept of 'free disposal hull' (FDH) of Tulkens and Vanden Eeckaut (1995), Figure 1 was able to be illustrated as a convex production possibility set.
} 
In order to draw a more detailed graph, directional distance function (DDF) is needed. Let $\vec{g}=\left(\vec{g}_{y}, \vec{g}_{b}\right)$ be a direction vector, with $\mathbf{g} \in R_{+}^{M} \times R_{+}^{J}$. Then, the directional distance function is defined as follows:

$$
\vec{D}\left(\boldsymbol{x}, \boldsymbol{y}, \boldsymbol{b} ; \vec{g}_{y}, \vec{g}_{b}\right)=\max \left\{\beta:\left(\boldsymbol{x}, \boldsymbol{y}+\beta \vec{g}_{y}, \boldsymbol{b}-\beta \vec{g}_{b}\right) \in P\right\}
$$

There is no correct answer to find a right directional vector, thus the reason for further research. As we mentioned, the directional distance function seeks a way to increase the desirable outputs while reducing the undesirable outputs at the same time. Accordingly, $\vec{g}=\left(\vec{g}_{y}, \vec{g}_{b}\right)$ determines the direction as shown in Figure 1.

\subsection{The MML model}

With the logic described above, we are able to define and decompose the MML index. In order to incorporate metafrontier and directional distance function concepts in the index computation, three definitions about benchmark technology sets are needed. These include: (1) contemporaneous benchmark technology, (2) inter-temporal benchmark technology and (3) global benchmark technology. The definition and notation used here are based on Oh (2010b)'s study, which in turn were originally developed by Tulkens and vanden Eeckaut (1995).

The first benchmark technology, a contemporaneous benchmark technology of the group $G_{\mathrm{h}}$ is defined as $P_{G_{h}}^{C^{t}}$, where the subscript h represents individual DMU, $\mathrm{h}=1, \ldots$, H. It can be described as $P_{G_{h}}^{C^{t}}=\left\{\left(\boldsymbol{x}^{t}, \boldsymbol{y}^{\boldsymbol{t}}, \boldsymbol{b}^{\boldsymbol{t}}\right) \mid \boldsymbol{x}^{\boldsymbol{t}}\right.$ can produce $\left.\left(\boldsymbol{y}^{\boldsymbol{t}}, \boldsymbol{b}^{\boldsymbol{t}}\right)\right\}$, where $t=1, \ldots, T$. The contemporaneous benchmark technology indicates a reference production set at time t. This set is made from observations at that time only for the group $\mathrm{G}_{\mathrm{h}}$.

The second benchmark technology, the inter-temporal benchmark technology of the group $G_{\mathrm{h}}$ is defined as $P_{G_{h}}^{i}$, in turn described as $P_{G_{h}}^{i}=P_{G_{h}}^{C^{1}} \cup P_{G_{h}}^{C^{2}} \cup P_{G_{h}}^{C^{3}} \cdots \cup P_{G_{h}}^{C^{T}}$. The inter-temporal benchmark technology consists of a single reference production set made from observations throughout the whole time period for the group $G_{h}$. There can be $\mathrm{H}$ distinct inter-temporal benchmark technologies. Industries in one intertemporal benchmark technology are assumed to be unable to easily access different inter-temporal benchmark technologies. As Figure 2 shows, we can know that the inter-temporal benchmark technology of a specific group of decision units could envelope its contemporaneous benchmark technologies.

The last benchmark technology, the global benchmark technology of all groups is defined as $P_{G_{h}}^{W}$. The global benchmark technology establishes the only reference production set made from observations throughout the entire time period for all groups. It can then be written as $P_{G_{h}}^{W}=P_{G_{1}}^{i} \cup P_{G_{2}}^{i} \cup P_{G_{3}}^{i} \cup \cdots \cup P_{G_{H}}^{i}$. As we can see from Figure 2, the global benchmark technology covers all technology groups and all its enveloping inter-temporal technologies. For the purpose of analysis, we assume that it is possible for industries to reach the global technology, both theoretically and potentially, although there may be obstacles in accessing other technologies.

The above three definitions allow us to formulate the MML index, which is an advanced form of the ML index. The contemporaneous ML index, which is based on the contemporaneous benchmark technology between the time periods $t$ and $t+1$ is defined as was suggested by Chung et al. (1997): 


$$
\begin{aligned}
& M L^{T}\left(\boldsymbol{x}^{t}, \boldsymbol{y}^{t}, \boldsymbol{b}^{t}, \boldsymbol{x}^{t+1}, \boldsymbol{y}^{t+1}, \boldsymbol{b}^{t+1}\right)=\frac{1+\overrightarrow{D_{C}^{T}}\left(\boldsymbol{x}^{t}, \boldsymbol{y}^{t}, \boldsymbol{b}^{t}\right)}{1+\overrightarrow{D_{C}^{T}}\left(\boldsymbol{x}^{t+1}, \boldsymbol{y}^{t+1}, \boldsymbol{b}^{t+1}\right)} \\
= & {\left[\frac{1+\vec{D}_{c}^{t}\left(\boldsymbol{x}^{t}, \boldsymbol{y}^{t}, \boldsymbol{b}^{t}\right)}{1+\vec{D}_{c}^{t}\left(\boldsymbol{x}^{t+1}, \boldsymbol{y}^{t+1}, \boldsymbol{b}^{t+1}\right)} \cdot \frac{1+\vec{D}_{c}^{t+1}\left(\boldsymbol{x}^{t}, \boldsymbol{y}^{t}, \boldsymbol{b}^{t}\right)}{1+\vec{D}_{c}^{t+1}\left(\boldsymbol{x}^{t+1}, \boldsymbol{y}^{t+1}, \boldsymbol{b}^{t+1}\right)}\right]^{\frac{1}{2}}=E C^{T} \cdot T C^{T} }
\end{aligned}
$$

where $\overrightarrow{D_{c}^{T}}$ means the contemporaneous distance directional function following the logic of direction vector $\vec{g}$. For simplicity, we replaced the directional distance function $\vec{D}\left(\boldsymbol{x}, \boldsymbol{y}, \boldsymbol{b} ; \vec{g}_{y}, \vec{g}_{b}\right)$ with $\vec{D}(\boldsymbol{x}, \boldsymbol{y}, \boldsymbol{b}) .{ }^{13}$ Also, the superscript $\mathrm{T}=\mathrm{t}, \mathrm{t}+1$ and subscript ' $c$ ' indicate the 'contemporaneous' situation. ${ }^{14}$

The geometric mean form of two consecutive contemporaneous ML productivity indices is typically used, expressed as $M L^{T}=\left(M L^{t} \cdot M L^{t+1}\right)^{1 / 2}$. This ML index can be decomposed into efficiency change (EC) and technical change (TC) components.

Through expansion of the logic of the ML index and adjustment of intertemporal and global benchmark technologies, the MML index can be derived as follows:

$$
M M L\left(\boldsymbol{x}^{t}, \boldsymbol{y}^{t}, \boldsymbol{b}^{t}, \boldsymbol{x}^{t+1}, \boldsymbol{y}^{t+1}, \boldsymbol{b}^{t+1}\right)=\frac{1+\vec{D}_{G}\left(\boldsymbol{x}^{t}, \boldsymbol{y}^{t}, \boldsymbol{b}^{t} ; \boldsymbol{y}^{t}, \boldsymbol{b}^{t}\right)}{1+\vec{D}_{G}\left(\boldsymbol{x}^{t+1}, \boldsymbol{y}^{t+1}, \boldsymbol{b}^{t+1} ; \boldsymbol{y}^{t+1}, \boldsymbol{b}^{t+1}\right)}
$$

where $\vec{D}_{G}\left(\boldsymbol{x}, \boldsymbol{y}, \boldsymbol{b} ; \vec{g}_{y}, \vec{g}_{b}\right)=\max \left\{\beta:\left(\boldsymbol{x}, \boldsymbol{y}+\beta \vec{g}_{y}, \boldsymbol{b}-\beta \vec{g}_{b}\right) \in P^{G}\right\}$ and period T $=\mathrm{t}, \mathrm{t}+1$. It shows that the global directional distance function is defined in the global technology set. To extract more information from the MML index, decomposition into three parts of productivity growth is needed. As a result, the MML equation is written as:

$$
\begin{aligned}
& M M L\left(\boldsymbol{x}^{t}, \boldsymbol{y}^{\boldsymbol{t}}, \boldsymbol{b}^{\boldsymbol{t}}, \boldsymbol{x}^{t+\mathbf{1}}, \boldsymbol{y}^{\boldsymbol{t}+\mathbf{1}}, \boldsymbol{b}^{\boldsymbol{t}+\mathbf{1}}\right)=\frac{1+\vec{D}_{G}\left(\boldsymbol{x}^{t}, \boldsymbol{y}^{\boldsymbol{t}}, \boldsymbol{b}^{\boldsymbol{t}}\right)}{1+\vec{D}_{G}\left(\boldsymbol{x}^{\boldsymbol{t}+\mathbf{1}}, \boldsymbol{y}^{\boldsymbol{t}+\mathbf{1}}, \boldsymbol{b}^{\boldsymbol{t}+\mathbf{1}}\right)} \\
& =\frac{1+\vec{D}_{C}^{t}\left(\boldsymbol{x}^{t}, \boldsymbol{y}^{\boldsymbol{t}}, \boldsymbol{b}^{t}\right)}{1+\vec{D}_{C}^{t+1}\left(\boldsymbol{x}^{\boldsymbol{t}+\mathbf{1}}, \boldsymbol{y}^{\boldsymbol{t}+\mathbf{1}}, \boldsymbol{b}^{\boldsymbol{t}+\mathbf{1}}\right)} \\
& \times\left\{\frac{1+\vec{D}_{I}^{t}\left(\boldsymbol{x}^{t}, \boldsymbol{y}^{t}, \boldsymbol{b}^{t}\right)}{1+\vec{D}_{C}^{t}\left(\boldsymbol{x}^{t}, \boldsymbol{y}^{t}, \boldsymbol{b}^{t}\right)} \times \frac{1+\vec{D}_{C}^{t+1}\left(\boldsymbol{x}^{t+1}, \boldsymbol{y}^{t+1}, \boldsymbol{b}^{t+\mathbf{1}}\right)}{1+\vec{D}_{I}^{t+1}\left(\boldsymbol{x}^{t+1}, \boldsymbol{y}^{\boldsymbol{t}+\mathbf{1}}, \boldsymbol{b}^{t+1}\right)}\right\} \\
& \times\left\{\frac{1+\vec{D}_{G}^{t}\left(\boldsymbol{x}^{t}, \boldsymbol{y}^{\boldsymbol{t}}, \boldsymbol{b}^{\boldsymbol{t}}\right)}{1+\vec{D}_{I}^{t}\left(\boldsymbol{x}^{t}, \boldsymbol{y}^{\boldsymbol{t}}, \boldsymbol{b}^{\boldsymbol{t}}\right)} \times \frac{1+\vec{D}_{I}^{t+1}\left(\boldsymbol{x}^{t+\mathbf{1}}, \boldsymbol{y}^{\boldsymbol{t}+\mathbf{1}}, \boldsymbol{b}^{t+\mathbf{1}}\right)}{1+\vec{D}_{G}^{t+1}\left(\boldsymbol{x}^{t+1}, \boldsymbol{y}^{t+\mathbf{1}}, \boldsymbol{b}^{t+1}\right)}\right\} \\
& =T E^{t+1} / T E^{t} \times B P R^{t+1} /{ }_{B P R^{t}} \times T G R^{t+1} / T G R^{t} \\
& =E C \times B P C \times T G C
\end{aligned}
$$

\footnotetext{
13 This replacement is applied with the MML index.

14 For comparison and analysis using both the ML and MML indices, we tried to explain the condition using the concept of "contemporaneous"
} 
The MML is decomposed into a number of components, each of which is described in the above Equation (10) and (11). Each of the three kinds of directional distance functions is based on each of the three benchmark technology sets.

In Equation (10), $\mathrm{TE}^{\mathrm{T}}$ means technical efficiency and $\mathrm{BPR}^{\mathrm{T}}$ indicates the best practice gap ratio which is derived by the gap between the contemporaneous benchmark technology and the inter-temporal benchmark technology in period T. $\mathrm{TGR}^{\mathrm{T}}$ is defined as the technology gap ratio, which is measured as the gap between the inter-temporal benchmark technology and the global benchmark technology in period $\mathrm{T}$.

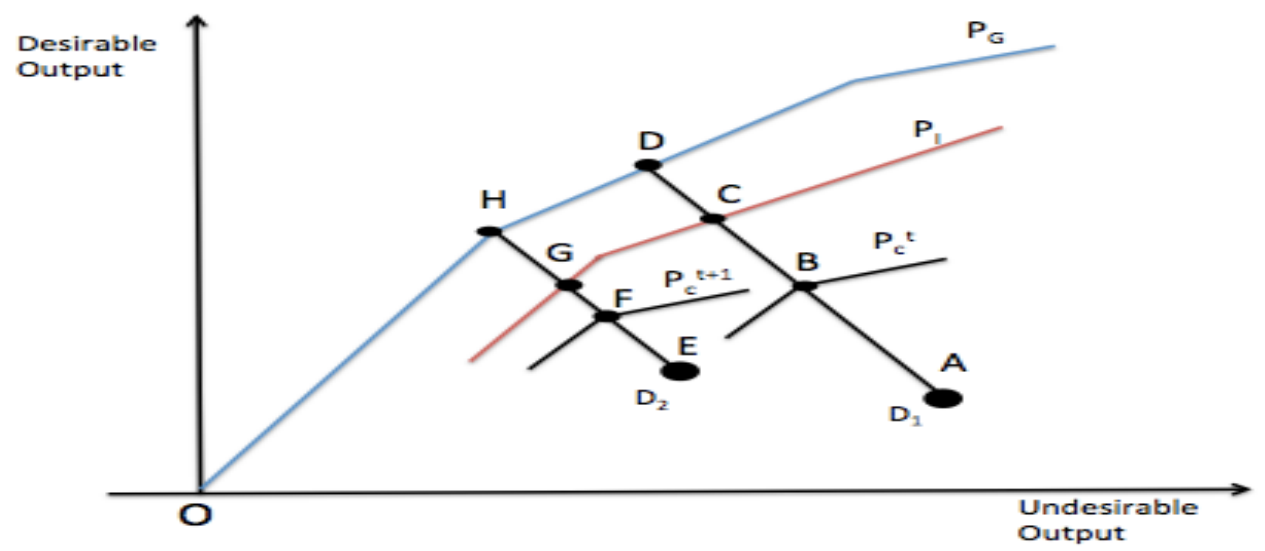

Figure 2 Three concepts of benchmark technology

In addition, Equation (10) can be drawn as Figure 2, and it shows the three concepts of benchmark technology simply. It represents one industry and two outputs during two time periods to measure productivity change.

Using Figure 2, we can derive MML and decomposition of components as below:

$$
\begin{gathered}
M M L\left(\boldsymbol{x}^{\boldsymbol{t}}, \boldsymbol{y}^{\boldsymbol{t}}, \boldsymbol{b}^{\boldsymbol{t}}, \boldsymbol{x}^{t+\mathbf{1}}, \boldsymbol{y}^{\boldsymbol{t + 1}}, \boldsymbol{b}^{\boldsymbol{t}+\mathbf{1}}\right)=[1+A D / 1+E H] \\
=\left(\frac{1+A B}{1+E F}\right) \times\left(\frac{1+A C / 1+A B}{1+E G / 1+E F}\right) \times\left(\frac{1+A D / 1+A C}{1+E H / 1+E G}\right)
\end{gathered}
$$

where Equation (12) shows three terms and which can be matched with the components of Equation (10) sequentially.

Through rewriting equation (10), we can get equation (11). Each term has a different meaning. At first, EC represents efficiency change and provides information on how much the gap to be closed at the contemporaneous benchmark technology at time $t+1$ relative to the previous period $t$. If EC exceeds 1 , it can be interpreted as efficiency gain and gets closer compare to the contemporaneous benchmark technology frontier that is economically called the 'catching up effect'.

Next, BPC, best practice gap change, tends to be regarded as innovation efficiency' or 'technology change' because it is measured by a change in the best practice gap ratio during the two periods and its representative value is also 1 . When BPC exceeds 1 , it means that the contemporaneous benchmark technology frontier has shifted towards the inter-temporal benchmark technology frontier and it can shift their contemporaneous benchmark frontier in a direction of producing more desirable outputs and fewer undesirable outputs.

TGC, technical gap change, denotes the 'technology catching-up effect' among the decision making units, and it is related with changing of an inter-temporal 
benchmark technology frontier and a global benchmark technology frontier during the two periods. When TGC is over 1 , it could be interpreted as a technological gap between any DMU at all periods, and the global frontier technology is reduced.

In order to calculate the MML index, the directional distance function should be estimated first. There are a number of representative ways that have been previously introduced by Chung et al. (1997), Lee et al. (2002), Kumar (2006) and Färe et al. (2007). Previous studies employed DEA with linear programming. As it was mentioned, the DEA has both advantages and disadvantages. The advantages of DEA are that it does not need a specific objective (production) function and directional distance function. These advantages provide more convenience to interpret the results and to release restrictions on parameters. Even though shadow price cannot be estimated by the DEA method, it is not a significant matter of this study, thus we followed the DEA with the linear programming calculation methodology suggested by Oh (2010a).

For concrete use of linear programming and obtaining information in terms of productivity growth, setting up several different linear programming are an essential part of the exercise. In this study, we should build six equations that are made up from a combination of three directional distance functions and two time periods at each DMU written as:

$$
\begin{gathered}
\vec{D}_{C, I, G}^{T}\left(\boldsymbol{x}^{U, T}, \boldsymbol{y}^{U, T}, b^{U, T}\right)=\max \left\{\beta:\left(\boldsymbol{x}^{U, T}, \boldsymbol{y}^{U, T}+\beta \vec{g}_{y}, \boldsymbol{b}^{U, T}-\beta \vec{g}_{b}\right) \in P\right\} \\
\text { s.t } \sum_{c o n} \lambda^{U, T} \cdot \boldsymbol{y}_{m}^{U, T} \geq(1+\beta) \boldsymbol{y}_{m}^{U^{\prime}, T}, \quad m=1, \cdots, M \\
\sum_{c o n} \lambda^{U, T} \cdot \boldsymbol{b}_{J}^{U, T}=(1-\beta) \boldsymbol{b}_{j}^{U^{\prime}, T}, \quad j=1, \cdots, J \\
\sum_{c o n} \lambda^{U, T} \cdot \boldsymbol{x}_{n}^{U, T} \leq \boldsymbol{x}_{n}^{U^{\prime}, T}, \quad n=1, \cdots, N \\
\lambda^{U} \geq 0
\end{gathered}
$$

where U represent each industry, $\sum_{c o n} \lambda^{U, T}$ indicates the condition for constructing a PPS and the $\lambda^{U, T}$ is the intensity variable which indicates at what intensity a particular activity must be employed in the construction of a PPS. The value of directional distance function, which is estimated by DEA type linear programming, is an optimal solution for the calculation and decomposition of the MML index.

\section{Empirical Analysis}

\subsection{Data resources and description}

According to the model outlined above, we employed fourteen industries and its five components of production consisting of output, $\mathrm{CO}_{2}$ emission, capital stock, labor and energy inputs in Korean industries over the period from 1981 to 2007. ${ }^{15}$ Output, capital stock, labor cost and energy are expressed in monetary forms, while $\mathrm{CO}_{2}$ in

\footnotetext{
${ }^{15}$ We have chosen variables that was considered by previous studies (Lozano and Gutiérrez, 2008; Zhou et al., 2010)
} 
metric tons. Classification of industries used in this study followed the division of detailed $\mathrm{CO}_{2}$ emission data provided by IEA $\mathrm{CO}_{2}$ emissions from Fuel Combustion Statistics. In order to match each sourced production component with classification of industries, we should take into consideration the Korean standard industry classification (KSIC) and the equivalent of International standard industry classification (ISIC) Rev4. Since the division of detailed $\mathrm{CO}_{2}$ emission data is based on ISCI Rev4, we need to make it consistent with the KSIC in order to merge the $\mathrm{CO}_{2}$ data with other output and inputs components of production.

We employed the data from 2011 KIP DB provided by the Korea productivity center for use as output, capital stock and energy input. We used labor input obtained from EUKLEMS ${ }^{16}$ data as KIP DB does not provide labor input. Although we could not use the same sourced data of production components, it did not cause problems in merging different data sets because the measurement method of KIP DB is based on EUKLEMS. All those components except $\mathrm{CO}_{2}$ emission are deflated by producer price index for transforming nominal values into real values. Table 1 shows classification of industries and descriptive summary statistics of the variables used.

Table 1. Descriptive statistics of the data, 1981 to $2007^{17}$

\begin{tabular}{|c|c|c|c|c|c|c|}
\hline ID & INDUSTRY & $\begin{array}{c}\text { OUPUT } \\
\text { (Billion } \\
\text { Won) } \\
\end{array}$ & $\begin{array}{c}\mathrm{CO}_{2} \\
\text { (Mt of } \\
\text { Ton) }\end{array}$ & $\begin{array}{c}\text { CAPITAL } \\
\text { (Billion } \\
\text { Won) } \\
\end{array}$ & $\begin{array}{c}\text { LABOR } \\
\text { (Billion } \\
\text { Won) } \\
\end{array}$ & $\begin{array}{c}\text { ENERGY } \\
\text { (Billion } \\
\text { Won) } \\
\end{array}$ \\
\hline 1 & Agriculture & $\begin{array}{l}35,041 \\
(4,639)\end{array}$ & $\begin{array}{c}6.195 \\
(2.814)\end{array}$ & $\begin{array}{c}40,264 \\
(18,781)\end{array}$ & $\begin{array}{l}2,406 \\
(412)\end{array}$ & $\begin{array}{c}968 \\
(180)\end{array}$ \\
\hline 2 & $\begin{array}{l}\text { Chemical and } \\
\text { petrochemical }\end{array}$ & $\begin{array}{c}40,502 \\
(25,736)\end{array}$ & $\begin{array}{c}7.507 \\
(3.203)\end{array}$ & $\begin{array}{c}31,405 \\
(21,282)\end{array}$ & $\begin{array}{c}4,427 \\
(2,520)\end{array}$ & $\begin{array}{c}7,014 \\
(3,316)\end{array}$ \\
\hline 3 & Construction & $\begin{array}{c}83,692 \\
(36,250)\end{array}$ & $\begin{array}{c}1.394 \\
(0.384)\end{array}$ & $\begin{array}{c}52,750 \\
(46,162)\end{array}$ & $\begin{array}{c}23,238 \\
(13,945)\end{array}$ & $\begin{array}{l}1,200 \\
(299)\end{array}$ \\
\hline 4 & Food and Tobacco & $\begin{array}{c}40,605 \\
(12,436)\end{array}$ & $\begin{array}{c}2.983 \\
(0.737)\end{array}$ & $\begin{array}{l}16,717 \\
(9,359)\end{array}$ & $\begin{array}{c}3,564 \\
(1,479)\end{array}$ & $\begin{array}{c}776 \\
(166)\end{array}$ \\
\hline 5 & Iron and steel & $\begin{array}{c}32,901 \\
(18,103)\end{array}$ & $\begin{array}{l}14.087 \\
(7.820)\end{array}$ & $\begin{array}{c}33,133 \\
(21,418)\end{array}$ & $\begin{array}{c}2,514 \\
(1,448)\end{array}$ & $\begin{array}{c}2,357 \\
(1,422)\end{array}$ \\
\hline 6 & Machinery & $\begin{array}{c}150,146 \\
(136,218)\end{array}$ & $\begin{array}{c}2.094 \\
(0.718)\end{array}$ & $\begin{array}{c}62,715 \\
(38,135)\end{array}$ & $\begin{array}{c}17,817 \\
(12,159)\end{array}$ & $\begin{array}{c}3,082 \\
(1,673)\end{array}$ \\
\hline 7 & $\begin{array}{l}\text { Non-energy use industry/ } \\
\text { transformation/energy }\end{array}$ & $\begin{array}{c}28,634 \\
(15,598)\end{array}$ & $\begin{array}{c}9.360 \\
(6.748)\end{array}$ & $\begin{array}{c}13,365 \\
(10,098)\end{array}$ & $\begin{array}{l}1,088 \\
(816)\end{array}$ & $\begin{array}{c}16,904 \\
(13,510)\end{array}$ \\
\hline 8 & Non-metallic minerals & $\begin{array}{l}13,501 \\
(6,928)\end{array}$ & $\begin{array}{l}13.863 \\
(4.567)\end{array}$ & $\begin{array}{c}19,009 \\
(12,281)\end{array}$ & $\begin{array}{c}2,379 \\
(1,101)\end{array}$ & $\begin{array}{l}1,728 \\
(806)\end{array}$ \\
\hline 9 & Non-specified industry & $\begin{array}{c}27,287 \\
(13,230)\end{array}$ & $\begin{array}{c}8.274 \\
(5.316)\end{array}$ & $\begin{array}{l}14,248 \\
(9,677)\end{array}$ & $\begin{array}{c}3,710 \\
(1,896)\end{array}$ & $\begin{array}{l}1,678 \\
(883)\end{array}$ \\
\hline 10 & Paper, pulp and printing & $\begin{array}{l}12,323 \\
(5,766)\end{array}$ & $\begin{array}{c}3.271 \\
(1.409)\end{array}$ & $\begin{array}{c}9,370 \\
(6,856)\end{array}$ & $\begin{array}{c}2,879 \\
(1,506)\end{array}$ & $\begin{array}{c}523 \\
(255)\end{array}$ \\
\hline 11 & Textile and leather & $\begin{array}{l}38,856 \\
(5,996)\end{array}$ & $\begin{array}{c}4.666 \\
(0.971)\end{array}$ & $\begin{array}{c}25,002 \\
(11,373)\end{array}$ & $\begin{array}{c}4,835 \\
(1,343)\end{array}$ & $\begin{array}{l}1,777 \\
(815)\end{array}$ \\
\hline
\end{tabular}

\footnotetext{
${ }^{16}$ EU country and industry level data set can be downloaded at http://www.euklems.net/

17 The category of non-energy use industry/transformation/energy refers to Coke, refined petroleum and nuclear fuel, and it is defined as non-energy in industry, transformation and other energy industry own use. The category of non-specified industry includes several industries, including rubber, plastics, other manufacturing, recycling and furniture.
} 


\begin{tabular}{llccccc}
12 & Transport & 41,556 & 55.729 & 37,696 & 9,416 & 5,521 \\
& & $(21,221)$ & $(27.875)$ & $(16,728)$ & $(5,296)$ & $(4,566)$ \\
13 & 52,596 & 1.620 & 45,790 & 7,468 & 974 \\
& \multirow{2}{*}{14} & Transport equipment & & & & \\
\multirow{2}{*}{ Wood and wood products } & 3,201 & 0.197 & 1,988 & 435 & $(5,305)$ & $(593)$ \\
& & $(902)$ & $(0.077)$ & $(1,062)$ & $(184)$ & $(33)$ \\
\hline
\end{tabular}

Note: Standard deviations in parenthesis

Table 1 reports summary statistics of the data including average and standard deviation of the variables. The summary shows that Machinery industry has the largest average value of output and capital stock among the sample industries. Transport industry generates the largest amount of $\mathrm{CO}_{2}$ emission; construction pays the largest amount of labor cost. Considering energy input, the combined Non-energy use industry/ transformation/energy stands as the dominant player in the market.

Under the assumption of general increasing trend, the value of standard deviation makes it possible to guess its dispersion and growth gap over the period from 1981 to 2007. The standard deviation of output of Machinery and Transport equipment is quite large, meaning that these industries are experiencing high grow rate compared with small standard deviation industries. Such pattern is consistent with the general development process of the Korean industry. ${ }^{18}$

\subsection{Controlling for DMUs heterogeneity}

ML index does not account for the heterogeneity originating from each unique production technology that a DMU have, however, the MML index considers heterogeneity of each $\mathrm{DMU}^{19}$ in production. In order to adjust for the heterogeneity and to estimate the MML index, we need to categorize DMUs into several specific technology groups.

After the grouping, each industry should have unique production technologies that make each industry to choose among different optimal components of inputs and outputs depending on their production environment, geographical locations and resource endowments (Huang et al., 2010). Therefore, some studies have employed geographical location to classify countries into different industry groups (Battese et al., 2004; O'Donnell et al., 2008; Oh and Lee, 2010; and Oh, 2012). The present study focuses on the intermediate level of aggregation, as geographical location does not explain the relationship between technology level and industries.

World Economic Forum 2010 (WEF, 2010), asserts that the main factor of technology development is to be determined by learning and absorbing new technological knowledge and expenditures on research and development (R\&D). Many studies related to technology, in this sense, use the level of $R \& D$ or establishment of research centers as a proxy of unique production technology. In a similar manner, Iyer and Tang (2006) and Chiu et al. (2012) used the technological competitiveness indicator and the average of annual income per capita to categorize the technology levels of group-specific production frontiers.

We follow similar approach described above in order to split the sample into four kinds of technology groups which were defined based on two criteria. The first

\footnotetext{
${ }^{18}$ From 1980’s to early 90’s, Korea had the fastest economic growth rate in the world. In particular, the industry export promotion policy explains the development outcome.

${ }^{19}$ Decision Making Unit (DMU) refers to industry in this study.
} 
criterion is $\mathrm{CO}_{2}$ emission per unit of energy input, and the second criterion is output per unit of labor (called labor productivity) ${ }^{20}$. The reason for choosing the first criterion is to be able to capture technological competitiveness of energy efficiency. The reason for choosing the second criterion is to categorize the profitability of production. Table 2 shows the industrial classification following the mentioned criterions.

Table 2. Classification of Industry groups

\begin{tabular}{llll}
\hline Group A & \multicolumn{1}{c}{ Group B } & \multicolumn{1}{c}{ Group C } & Group D \\
\hline \hline Chemical and petrochemical & Construction & Agriculture & Non-metallic minerals \\
$\begin{array}{l}\text { Non-energy use industry/ } \\
\text { transformation/energy }\end{array}$ & Machinery & Food and Tobacco & Non-specified industry \\
Transport equipment & Textile and leather & Iron and steel & Transport \\
& Wood and wood products & Paper, pulp and printing & \\
\hline
\end{tabular}

As it can be seen in Table 2, Group A has the feature that higher energy efficiency is attributed to environmental friendliness and high profitability nature of activities. It means that Group A characterizes industries that have environmentally comparative advantages of technology. On the contrary, Group D has the opposite character compared with that of Group A. Thus, Group D is deemed to belong to industries that environmentally have comparative technological disadvantages.

Group B has comparative advantages in terms of energy efficiency. However, it is characterized as a relatively low profitability industry. Group C holds opposite characteristics to Group B. Consequently, Group C has comparative disadvantages in terms of energy efficiency and high profitability industry.

\subsection{MML index compared with ML index}

In contrast to the conventional ML index, the MML index can measure the environmentally sensitive productivity index. This means that we are expected to capture the effect of $\mathrm{CO}_{2}$ emission on the production of desirable output. Therefore, we focused on comparing industry's productivity measured by the ML index and the MML index during same study period to isolate the effects of $\mathrm{CO}_{2}$ emissions.

Prior to the comparative analysis, we report the average level and growth rate of each production related component for the period of 1981 to 2007 by classification of industry groups.

Table 3. Summary statistics of key indicators by industry groups

\begin{tabular}{cccccc}
\hline GROUP & $\begin{array}{c}\text { OUTPUT } \\
\text { (Billion Won) }\end{array}$ & $\begin{array}{c}\mathrm{CO}_{2} \\
\text { (Mt of Ton) }\end{array}$ & $\begin{array}{c}\text { CAPITAL } \\
\text { (Billion Won) }\end{array}$ & $\begin{array}{c}\text { LABOR } \\
\text { (Billion Won) }\end{array}$ & $\begin{array}{c}\text { ENERGY } \\
\text { (Billion Won) }\end{array}$ \\
\hline \hline \multirow{2}{*}{ Group A } & 40,577 & 6.162 & 30,186 & 4,328 & 8,297 \\
& $(28,023)$ & $(3.877)$ & $(22,263)$ & $(2,886)$ & $(5,806)$ \\
Group B & 68,974 & 2.088 & 35,614 & 11,581 & 1,545 \\
Group C & $(44,841)$ & $(0.537)$ & $(24,183)$ & $(6,908)$ & $(705)$ \\
\hline
\end{tabular}

20 We used the number of labor instead of cost of labor. Cost of labor accounts for the differences in wages of labor across different industries. The difference reflects quality or human capital of labor. 


\begin{tabular}{lccccc}
\hline & $(10,236)$ & $(3.195)$ & $(14,104)$ & $(1,211)$ & $(506)$ \\
\multirow{2}{*}{ Group D } & 27,448 & 25.955 & 23,651 & 5,168 & 2,975 \\
& $(13,793)$ & $(12.586)$ & $(12,896)$ & $(2,764)$ & $(2,085)$ \\
\hline
\end{tabular}

Note: Standard deviations in parenthesis.

In Table 3, we can observe some specific features of each industry group. As expected, each group has different features. Group A can be regarded as the largest consumer of energy input, taking the second rank in both the levels of $\mathrm{CO}_{2}$ emission and output level. Group D shows the lowest level of output and energy input, whereas it emits more $\mathrm{CO}_{2}$ than any other group. Because of the different features of Group B and Group C, they show the opposite tendency in the components used and its outcome. In particular, Group B is the largest consumer of labor input while group C is the smallest user of labor input.

When looking at the standard deviation, the table shows evidence of rapid growth during the study period. In order to verify the features of rapid growth of industries in Korea, Table 4 reports the average annual growth rate of the three inputs, output and emission indicators by each industry group.

Table 4. Average annual percentage growth rate of indicators by industry groups.

\begin{tabular}{lccccc}
\hline Group & Output & $\mathrm{CO}_{2}$ & Capital & Labor & Energy \\
\hline \hline Group A & 10.89 & 13.47 & 12.79 & 13.08 & 11.62 \\
Group B & 6.93 & 2.84 & 10.64 & 8.61 & 4.84 \\
Group C & 5.84 & 4.30 & 9.56 & 7.37 & 6.00 \\
Group D & 8.65 & 8.56 & 9.54 & 9.36 & 9.49 \\
\hline
\end{tabular}

Using Table 4, we can see that industry Group A has the feature of energy efficiency during the whole period but the average growth rate of $\mathrm{CO}_{2}$ is higher than that of energy input. The average growth rate of output is lower than the growth rate of inputs of capital, labor and energy. The other groups also show different features than we thought initially. Thus, we derived results such that we account for the possibility that the character of groups might be changed as time elapses. Therefore, for detailed analysis related to the purpose of policy adoption with respect to time lapse, in Section 5.4, the period is divided into three sub-periods each consisting of one decade.

We estimated the geometric mean of ML and MML indices and decomposed both indices into their underlying components. The gap of PC $(\triangle \mathrm{PC})$ is decomposed into the $\mathrm{CO}_{2}$ emission effect and the heterogeneity effect. If any industry is identified to have a negative $\triangle \mathrm{PC}$, we consider the industry to be good at controlling $\mathrm{CO}_{2}$ emission or has an advanced environment friendly technology in the respective study period. The results are reported in Table 5.

Table 5. Productivity growth computed based on ML index and MML index methods for the period 19812007.

\begin{tabular}{lllllllll|}
\hline \multirow{3}{*}{ Group } & Industry & \multicolumn{4}{c}{ ML index } & \multicolumn{4}{c}{ MML index } & $\Delta$ PC $^{21}$ \\
\cline { 2 - 8 } & & EC & TC & PC & EC & BPC & TGC & PC \\
\hline \hline
\end{tabular}

${ }^{21} \Delta P C=P C \_M L-P C \_M M L$ 


\begin{tabular}{|c|c|c|c|c|c|c|c|c|c|}
\hline $\mathrm{C}$ & Agriculture & 1.0017 & 0.9963 & 0.9980 & 1.0000 & 0.9994 & 1.0001 & 0.9995 & -0.0015 \\
\hline A & $\begin{array}{l}\text { Chemical and } \\
\text { petrochemical }\end{array}$ & 1.0247 & 0.9874 & 1.0118 & 1.0000 & 1.0083 & 1.0007 & 1.0090 & 0.0028 \\
\hline B & Construction & 1.0000 & 0.9877 & 0.9877 & 1.0000 & 0.9983 & 0.9988 & 0.9971 & -0.0094 \\
\hline $\mathrm{C}$ & $\begin{array}{l}\text { Food and } \\
\text { Tabaco }\end{array}$ & 0.9971 & 0.9931 & 0.9902 & 1.0000 & 1.0000 & 0.9983 & 0.9983 & -0.0081 \\
\hline $\mathrm{C}$ & Iron and steel & 0.9995 & 0.9888 & 0.9883 & 1.0000 & 0.9876 & 0.9993 & 0.9862 & 0.0021 \\
\hline B & Machinery & 1.0264 & 1.0070 & 1.0336 & 1.0014 & 1.0175 & 1.0011 & 1.0200 & 0.0135 \\
\hline A & $\begin{array}{l}\text { Non-energy use } \\
\text { industry/transfor } \\
\text { mation/energy }\end{array}$ & 1.0000 & 0.9654 & 0.9654 & 1.0000 & 0.9857 & 0.9989 & 0.9846 & -0.0192 \\
\hline $\mathrm{D}$ & $\begin{array}{l}\text { Non-metallic } \\
\text { minerals }\end{array}$ & 1.0177 & 0.9859 & 1.0034 & 1.0000 & 0.9930 & 1.0082 & 1.0012 & 0.0022 \\
\hline $\mathrm{D}$ & $\begin{array}{l}\text { Non-specified } \\
\text { industry }\end{array}$ & 1.0037 & 0.9869 & 0.9906 & 1.0000 & 1.0027 & 0.9932 & 0.9959 & -0.0053 \\
\hline $\mathrm{C}$ & $\begin{array}{l}\text { Paper, pulp and } \\
\text { printing }\end{array}$ & 0.9775 & 0.9864 & 0.9642 & 0.9822 & 1.0000 & 1.0100 & 0.9920 & -0.0277 \\
\hline B & $\begin{array}{l}\text { Textile and } \\
\text { leather }\end{array}$ & 0.9974 & 0.9932 & 0.9907 & 1.0000 & 1.0000 & 0.9935 & 0.9935 & -0.0028 \\
\hline $\mathrm{D}$ & Transport & 1.0117 & 1.0102 & 1.0221 & 1.0000 & 1.0000 & 0.9999 & 0.9999 & 0.0221 \\
\hline A & $\begin{array}{l}\text { Transport } \\
\text { equipment }\end{array}$ & 1.0122 & 1.0107 & 1.0231 & 1.0000 & 1.0006 & 1.0133 & 1.0139 & 0.0092 \\
\hline B & $\begin{array}{l}\text { Wood and wood } \\
\text { products }\end{array}$ & 0.9921 & 0.9816 & 0.9738 & 0.9778 & 0.9997 & 1.0105 & 0.9877 & -0.0139 \\
\hline & Average & 1.0044 & 0.9915 & 0.9959 & 0.9972 & 0.9995 & 1.0018 & 0.9985 & -0.0026 \\
\hline
\end{tabular}

Note: Efficiency change (EC), technical change (TC), productivity change (PC), best practice gap change (BPC), and technology growth ratio change (TGC).

In looking at the result of the ML index, we noted that EC of many industries exceed 1 and the overall average level of EC is 1.00443. TC of most of industries are lower than 1, except for Machinery, Transport and Transport equipment. According to the result of the ML index, EC, the catching up effect, contributes more to a higher level of PC than TC, resulting in technology advancement. It is interpreted as using more input factors to expand the production level leads to achieve higher productivity growth than investments aimed at achieving technology advancement.

However, decomposition of the MML index tells quite a different story compared to the results of the ML index. The average of EC in the MML index is estimated to be below 1 and BPC and TGC are close and greater than 1. Thus, the catching up effect determined by the value of EC does not contribute much in the case of the ML index, and technical progress becomes a more important factor when we consider $\mathrm{CO}_{2}$ emission as an undesirable output related to production. 
To be more specific, only Machinery industry gained EC over 1 . As a result, this industry catches up with the contemporaneous benchmark technology frontier. Also, Chemical and Petrochemical, Machinery, Non-specified, and Transport equipment industries have BPC values larger than 1 which is interpreted as gain from innovation efficiency and technical progress. It is worth to mention that at last, Agriculture, Chemical and Petrochemical, Machinery, Non-metallic minerals, Paper, Pulp and Printing, Transport equipment, Wood and Wood product industries are shown to have the technology catching-up effects. Following this finding, Chemical and Petrochemical, Machinery and Transport equipment industries can be regarded as global innovators. ${ }^{22}$

As a result, the value of PC is a combination of EC, BPC and TGC, and only four industries including Chemical and Petrochemical, Machinery, Non-metallic minerals, and Transport equipment gain positive productive growth. Interestingly those industries have negative $\triangle \mathrm{PC}$, meaning that they did not prepare well along the policy of reducing $\mathrm{CO}_{2}$ emission or that the policy may be an obstacle to gaining higher productivity. Therefore, we can consider that the policy related with $\mathrm{CO}_{2}$ emission make the gap to decrease between industries with PC greater than 1 and those below 1 .

Table 6. MML index result and its decomposition by groups of industries

\begin{tabular}{lccccc}
\hline GROUP & EC & BPC & TGC & PC & $\Delta$ PC \\
\hline \hline A & 1.0000 & 0.9982 & 1.0043 & 1.0025 & -0.0024 \\
B & 0.9948 & 1.0039 & 1.0010 & 0.9996 & -0.0031 \\
C & 0.9955 & 0.9968 & 1.0019 & 0.9940 & -0.0088 \\
D & 1.0000 & 0.9986 & 1.0005 & 0.9990 & 0.0063 \\
\hline
\end{tabular}

Note: Efficiency change (EC), productivity change (PC), best practice gap change (BPC), and technology growth ratio change (TGC), $\triangle P C=P C_{-} M L-P C_{-} M M L$.

In order to strengthen the analysis MML index, we tried to divide the industries into homogenous groups. Table 6 shows how different PC effects are calculated. Table 6 shows the results in which all of the groups except Group D have higher PC than the case when $\mathrm{CO}_{2}$ emission was not considered in the measurement of productivity. Also, as expected, the results show that the group that has a technical advantages could gain higher PC. The average rate of productivity growth of Group A $(0.25 \%)$ was the highest and that of Group C $(-0.60 \%)$ was the lowest. Group B and Group D have the second and third highest rates of productivity growth. However, they also show negative productivity growth. A detailed form of Table 6 in a disaggregated form is provided in Appendix A.

In looking at different aspects of decomposition of productivity change, it is noted that Group A has the highest TGC (0.43\%) of over 1 and a high PC value even though EC and BPC do not exceed 1. This finding indicates that the main factor of enhancement of PC would be TGC, the technical gap change, which captures the technology catching up effect among all industries. This can be the case, despite a technological gap between any DMUs at all periods and the global frontier technology is reduced. The average rate of best practice technology gap change in Group B is the highest (0.39\% per year) and it serve as the only group which has a BPC value exceeding 1 . Another term related to technology progress, namely TGC, also show numbers over unity. It indicates that Group B is good at inventing in new

22 When both terms, BPC and TGC, exceed 1, it can be called 'global innovator'. 
technology or innovation, rather than reducing their endowed inputs to catch up with the frontier technology. On the other hand, Group C and D showed similar decomposition results that the PC of both Groups did not reach the unity value, and BPC could not help to raise its PC value. These groups do not show a better efficiency change, whereas the indicator of technical gap change became better. This implies that both groups were not shown to be good at catching up with the frontier technology using more endowed inputs, rather due to innovation and technology advancement they have reached closer to the global frontier technology.

\subsection{Further analysis of the result}

In Section 5.3, the results of MML by groups of industries were analyzed and as a result we have been able to add one more condition to analyze the results in a more detailed form. As we mentioned above, Korea has industrialized within a very short period of time and during the process, the industrial structure has changed much. Since the 90's, Korea has realized that quality of economic growth is more important than quantity expansion of the economy, thus the country began to regulate air pollution in earnest since mid-90's. In order to achieve a higher policy effect on productivity, we split the study period into three sub-periods, corresponding to three decades. This allowed to capture the heterogeneity across both industry groups and decades.

Table 7 reports the results of the ML and MML indices by time periods. The overall result in a more detailed form is presented in Appendix B.

Table 7. ML and MML indices result and their underlying components by time periods

\begin{tabular}{ccccccccc}
\hline & \multicolumn{3}{c}{ ML INDEX } & \multicolumn{7}{c}{ MML INDEX } & \multirow{2}{*}{$\Delta$ PC } \\
\cline { 2 - 7 } & EC & TC & PC & EC & BPC & TGC & PC & \\
\hline \hline $1981-2007$ & 1.0053 & 0.9914 & 0.9968 & 0.9976 & 0.9994 & 1.0019 & 0.9988 & -0.0020 \\
$1981-1989$ & 1.0102 & 0.9799 & 0.9897 & 1.0003 & 0.9802 & 1.0132 & 0.9930 & -0.0033 \\
$1990-1999$ & 1.0096 & 0.9925 & 1.0016 & 0.9970 & 1.0101 & 0.9979 & 1.0047 & -0.0031 \\
$2000-2007$ & 0.9966 & 1.0004 & 0.9971 & 0.9957 & 1.0061 & 0.9961 & 0.9976 & -0.0005 \\
\hline
\end{tabular}

Note: Efficiency change (EC), technical change (TC), productivity change (PC), best practice gap change (BPC), and technology growth ratio change (TGC), $\triangle P C=P C_{-} M L-P C_{-} M M L$.

As it is shown in Table 7, we can demonstrate more clearly what we have previously discussed. Both of the two ML and MML indices indicate that EC is getting smaller as time elapses and the proportion of technology effect on PC becomes greater as time elapses. In the ML index section, EC is the highest (1.02\%) in the 1980's and the lowest $(-0.34 \%)$ in the 2000's. On the other hand, TC is the highest $(0.04 \%)$ in the 2000's and the lowest level $(-2.01 \%)$ is attributed to the 1980's. In the case of the MML index, the highest EC value among the three decades is $0.03 \%$ in the 1980's and the lowest EC value is $-0.43 \%$ appearing in the 2000's. The best practice gap change shows the highest value in the 1990's and the lowest (-1.98\%) in the 1980's. TGC in the 1980's shows a good result in catching up with the frontier technology, rather than at innovating.

According to Table 7, indicators related to technical progress are more important factors to maintain or increase the productivity change, rather than factor inputs in the 
form of more endowment resources that industries can use in their production activities.

In summary, we can derive implicit conclusions through Appendix A. The highest MML index among all industries and time periods is $4.5 \%$ in Machinery in the 90's and such a result was caused by its high value of BPC (5.6\%). The dramatic change at $\triangle \mathbf{P C}$ is shown in Transport (8.3\%) in the 2000's, and Agriculture (-6.7\%) in the 90's. It can be deduced that Transport industry was tended to rely on the technical level of product itself such as vehicles, trains, airplanes, ships and so on. Also, technology related with reducing $\mathrm{CO}_{2}$ emission did not follow the demand of transportation. While Agriculture in the 90's is able to be interpreted as best well prepared and adoptable industry in the era of reducing $\mathrm{CO}_{2}$ emission

In the 2000s, some of the industries that stressed against environmental regulation showed evidence to have the biggest gap between ML and MML indices. Representatively, the gap result of Iron and Steel and Machinery industries in the 2000's is about $2.4 \%$ and $3.0 \%$. These industries are interpreted to have a negative effect on policy introduced in reducing $\mathrm{CO}_{2}$ emission. In the 2000's, the industries have no more room to promote PC by using the advantages arising from EC.

To summarize, the results in the disaggregated form for each industry group are shown in Appendix B. In Table 6, Group C shows the lowest PC in the whole period, even lower than Group D. However, in Appendix B, especially in the case of the ML index, $\mathrm{PC}$ of Group $\mathrm{C}$ shows a big jump with large positive effects on $\mathrm{CO}_{2}$ emission. On the other hand, Group D faces trouble as time passes.

According to the criteria of grouping and $\triangle P C$ in Appendix $\mathrm{B}$, we can derive an implicit conclusion that environment policy effects obviously occurred in the 2000's. Many environmental policies started in the 90's and it made different aspects between before the 80's and 2000's. The groups with comparatively higher profitability (Group A and C) are better able to invest in technological progress than others. Indeed, the lower profitability groups, Group B and Group D, show a positive value of $\triangle P C$ in the 2000's. This means that they suffered from changing their production way in order to adapt to environmental policies which was related with their level of profitability.

\section{Conclusion}

This study was constructed to find evidence about justification of environmental policies. In order to achieve this, the MML index was employed to capture environmentally sensitive measures of productivity and compared them with the ML index to analyze productivity at the industry level. In comparing the results with ML, we were able to identify which industry and industry groups did experience technological progress during the study period.

Our results provide decomposed productivity growth into efficiency change, technology change and part of technology change divided into innovation efficiency and technology catch up effect. Through MML results, we found that half of industries have increased the average productivity grow rate, while others experienced decrease productivity in the whole period. Nevertheless, since $\mathrm{CO}_{2}$ emission was thought as a constraint on production, MML has a higher productivity value than the ML approach. This result indicates that most of industries carried out investment aimed at reducing $\mathrm{CO}_{2}$. This shows that Korean industrial sectors are regarded as well prepared in adapting to new and restrictive environmental policies. 
It is noted that, industries that can be regarded as the primary contributor to the Korean economy growth such as Chemical and Petrochemical, Machinery, Transport equipment industries had problems in facing the tightened policy. The primary contributors like these industries have the wide spill-over effect of investment in technology. ${ }^{23}$ For leading and solving the matter of the environment, government and other industries need to set up favorable environment policies for the primary contributors to promote them to invest in the development of new technologies. ${ }^{24}$

Considering the analysis by sub-periods, we could find evidence of heterogeneity among industrial sectors. The groups with the high level of technology that use energy efficiently tends to get a higher annual rate of productivity change. We can understand the fact that the higher profitability group tends to have more surplus fund to invest in promoting technological progress and to utilize technology to use energy more efficiently. Furthermore, such tendency is clearly evident as time passes. It could be interpreted as restructuring at the industry level changes the industries production and environmental conditions.

After 2015, Korea may be obliged to reduce GHG emissions. In that situation, each industry would be faced by new market environmental conditions in earnest. In order to maintain global competitiveness, comprehensive investment programs to change production processes or to innovate new products and processes, should be achieved in the near future. In conclusion, the government has to take focus on supporting the primary contributors in the short-run for maintaining competitiveness against the global market. In the long-run, the government also should care about technology acquisition of lower profitability industries which do not have enough funds to invest in new energy saving and environment friendly technology

This study attempted to make a contribution to the literature by considering undesirable output in the calculation of productivity growth at the industry level. However, it could not present clearly the interaction process of desirable output and undesirable output, due to necessary excessive assumptions. In addition, we were not able to consider the issue of manufacturing production relocated abroad ${ }^{25}$. Thus, $\mathrm{CO}_{2}$ could be underestimated and productivity change might have been overestimated. The data set used here has a limitation in terms of partial data availability at the industry level. In addition, because of the data availability problem, we could not employ other inputs like material, services and information technology. Consequently, the results could be biased due to the reasons of lack of full information about the production structure of industries. We will take consideration of these limitations in our followup study.

Acknowledgement: The authors wish to thank D.H Oh for comments and suggestions that have contributed to improving the paper.

\footnotetext{
${ }^{23}$ The Effect of R\&D Expenditure: An Input-Output Analysis. Science and Technology Policy Institute. 2008-2010.

${ }^{24}$ Krautzberger L., Wetzel, H. (2012) analyzed the CO2-sensitive productivity growth of the commercial transport industry in 16 member states of the European Union and in Norway for the period 1995-2006. They found productivity decreasing trend on average.

${ }^{25}$ See also Grimes, P., 2003, Exporting the Greenhouse: Foreign Capital Penetration and CO2 Emissions 1980-1996, Journal of World-Systems Research, 261-275.
} 


\section{References}

Arcelus, F.J., Arocena P., 2005. Productivity differences across OECD countries in the presence of environmental constraints. Journal of Operational Research Society 56, 1352-1362.

Battese, G.E., Rao, D.S.P., 2002. Technology gap, efficiency, and a stochastic metafrontier function. International Journal of Business and Economics 1, 87-93.

Battese, G.E., Rao, D.S.P., O'Donnell, C.J., 2004. A metafrontier production function for estimation of technical efficiencies and technology gaps for firms operating under different technologies. Journal of Productivity Analysis 21, 91-103.

Brock, W.A., LeBaron, B., 1996. A dynamic structural model for stock return volatility and trading volume. Review of Economics and Statistics 78, 94-110.

Chiu, C.E., Liou, J.L., Wu, P.I., Fang, C.L., 2012. Decomposition of the environmental inefficiency of the Metafrontier with undesirable output. Energy Economics 34, 1391-1399

Coelli, T.J., Rao, D.S.P., O’Donnell, C.J., Battese, G.E., 2005. Introduction to efficiency and productivity analysis, 2nd edition. Springer, Heidelberg.

Chung, Y.H., Färe, R., 1995, Productivity and Inseparable Outputs: A Directional Distance Function Approach, Discussion Paper Series No. 95-24 November.

Chung, Y.H., Färe, R., Grosskopf, S., 1997. Productivity and undesirable outputs: a directional distance function approach. Journal of Environmental Management 51, 229-240.

Färe, R., Grosskopf, S., Norris, M., Zhang, Z., 1994. Productivity growth, technical progress, and efficiency change in industrialized countries. American Economic Review 84, 66-83.

Färe, R., Grosskopf, S., Noh, D.-W., Weber, W., 2005. Characteristics of a polluting technology: theory and practice. Journal of Econometrics 126, 469-492.

Färe, R., Grosskopf, S., Pasurka Jr, C.A., 2001., Accounting for air pollution emissions in measures of state manufacturing productivity growth. Journal of Regional Science 41, 381-409.

Färe, R., Grosskopf, S., Pasurka Jr, C.A., 2007. Environmental production functions and environmental directional distance functions. Energy 32, 1055-1066.

Färe, R., Grosskopf, S., Weber, W.L., 2006. Shadow prices and pollution costs in U.S. agriculture. Ecological Economics 56, 89-103.

Grimes, P., 2003. Exporting the Greenhouse: Foreign Capital Penetration and CO2 Emissions 1980-1996, Journal of World-Systems Research, 261-275

Hsieh, D., 1991. Chaos and nonlinear dynamics: applications to financial markets. Journal of Finance 47, 1145-1189.

Huang, Y.J., Chen, K.H., Yang, C.H., 2010. Cost efficiency and optimal scale of electricity distribution firms in Taiwan: an application of metafrontier analysis. Energy Economics 32, 15-23.

Iyer, K., Rambaldi, A., Tang, K.K., 2006. Globalization and the Technology Gap: 
Regional and Time Evidence, Leading Economic and Managerial Issues Involving Globalization. Nova Science New York, United States, pp. 213-227.

Kim, S., Lee, K., Nam, K., 2010. The relationship between CO2 emissions and economic growth: the case of Korea with nonlinear evidence. Energy Policy 38, 5938-5946.

Kumar, S., 2006. Environmentally sensitive productivity growth: a global analysis using Malmquist-Luenberger index. Ecological Economics 56, 280-293.

Lee, J.D., Park, J.B., Kim, T.Y., 2002. Estimation of the shadow prices of pollutants with production/environment inefficiency taken into account: a nonparametric directional distance function approach, Journal of Environmental Management 64, 365-375.

Krautzberger L., Wetzel, H., 2012. Transport and CO2: productivity growth and carbon dioxide emission in the European commercial transport industry, Environment and Resource Economics 53, 435-454.

Lozano, S., Gutiérrez, E., 2008. Non-parametric frontier approach to modelling the rela- tionships among population, GDP, energy consumption and CO2 emissions. Ecological Economics, 66, 687-699.

Nakano, M., Managi, S., 2008. Regulatory reforms and productivity: an empirical analysis of the Japanese electricity industry. Energy Policy 36, 201-209.

Oh, D.H., 2010a. A global Malmquist-Luenberger productivity index. Journal of Productivity Analysis 34, 183-197.

Oh, D.H., 2010b. A metafrontier approach for measuring an environmentally sensitive productivity growth index, Energy Economics 32 146-157.

Oh, D.H, Heshmati, A., 2010. A sequential Malmquist-Luenberger productivity index: Environmentally sensitive productivity growth considering the progressive nature of technology. Energy Economics 32, 1345-1355.

Oh, D.H., Lee, J.D., A metafrontier approach for measuring Malmquist productivity index. Empirical Economics (forthcoming).

Oh, W., Lee, K., 2004a. Causal relationship between energy consumption and GDP revisited: the case of Korea 1970-1999. Energy Economics 26, 51-59.

Oh, W., Lee, K., 2004b. Energy consumption and economic growth in Korea: testing the causality relation. Journal of Policy Modeling 26, 973-981.

Pasurka, C.A., 2006. Decomposing electric power plant emissions within a joint production framework. Energy Economics 28, 26-43.

Tulkens, H., van den Eeckaut, P., 1995. Non-parametric efficiency, progress and regress measures for panel data: methodological aspects. European Journal of Operational Research 80, 474-499.

Sueyoshi, T., Goto, M., 2010. Should the US clean air act include CO2 emission control?: Examination by data envelopment analysis. Energy Policy 38, 59025911.

Weber, W., Domazlicky, B., 2001. Productivity growth and pollution in state manufacturing. Review of Economics and Statistics 83, 195-199. 
Yang CH., Tseng YH,. Chen CP., 2011. Environmental Regulations, induced R\&D, and Productivity: Evidence from Taiwan's Manufacturing Industries. Working Paper Series Vol. 2011-18, November 2011.

Zhou, P., Ang, B.W., Han, J.Y., 2010. Total factor carbon emission performance: a Malmquist index analysis. Energy Economics 32, 194-201. 
APPENDIX A. ML and MML indices results and their components by industries, industry groups and periods of time

\begin{tabular}{|c|c|c|c|c|c|c|c|c|c|c|}
\hline \multirow{2}{*}{ GROUP } & \multirow{2}{*}{ INDUSTRY } & \multirow{2}{*}{ PERIOD } & \multicolumn{3}{|c|}{ ML index } & \multicolumn{4}{|c|}{ MML index } & \multirow{2}{*}{$\Delta \mathbf{P C}$} \\
\hline & & & EC & TC & PC & EC & BPC & TGC & PC & \\
\hline \multirow{11}{*}{ A } & \multirow{4}{*}{$\begin{array}{l}\text { Chemical } \\
\text { and } \\
\text { petrochemic } \\
\text { al }\end{array}$} & 1981-2007 & 1.025 & 0.987 & 1.012 & 1.000 & 1.008 & 1.001 & 1.009 & 0.003 \\
\hline & & 1981-1989 & 1.036 & 0.971 & 1.006 & 1.000 & 0.987 & 1.017 & 1.004 & 0.002 \\
\hline & & 1990-1999 & 1.046 & 0.990 & 1.035 & 1.000 & 1.029 & 0.993 & 1.022 & 0.013 \\
\hline & & 2000-2007 & 0.987 & 1.001 & 0.988 & 1.000 & 1.004 & 0.994 & 0.998 & -0.010 \\
\hline & \multirow{3}{*}{$\begin{array}{l}\text { Non-energy } \\
\text { use } \\
\text { industry/ } \\
\text { transformati } \\
\text { on/energy }\end{array}$} & 1981-2007 & 1.000 & 0.965 & 0.965 & 1.000 & 0.986 & 0.999 & 0.985 & -0.019 \\
\hline & & $\begin{array}{l}1981-1989 \\
1990-1999\end{array}$ & $\begin{array}{l}1.000 \\
1.000\end{array}$ & $\begin{array}{l}0.972 \\
0.968\end{array}$ & $\begin{array}{l}0.972 \\
0.968\end{array}$ & $\begin{array}{l}1.000 \\
1.000\end{array}$ & $\begin{array}{l}1.000 \\
0.974\end{array}$ & $\begin{array}{l}0.998 \\
1.001\end{array}$ & $\begin{array}{l}0.998 \\
0.975\end{array}$ & $\begin{array}{l}-0.025 \\
-0.007\end{array}$ \\
\hline & & 2000-2007 & 1.000 & 0.955 & 0.955 & 1.000 & 0.987 & 0.997 & 0.984 & -0.029 \\
\hline & \multirow{4}{*}{$\begin{array}{l}\text { Transport } \\
\text { equipment }\end{array}$} & 1981-2007 & 1.012 & 1.011 & 1.023 & 1.000 & 1.001 & 1.013 & 1.014 & 0.009 \\
\hline & & 1981-1989 & 0.987 & 1.015 & 1.002 & 1.000 & 0.996 & 1.040 & 1.036 & -0.034 \\
\hline & & 1990-1999 & 1.047 & 1.012 & 1.059 & 1.000 & 1.005 & 1.008 & 1.013 & 0.047 \\
\hline & & $2000-2007$ & 0.996 & 1.004 & 1.000 & 1.000 & 1.000 & 0.993 & 0.993 & 0.006 \\
\hline \multirow{16}{*}{ B } & \multirow{4}{*}{$\begin{array}{l}\text { Constructio } \\
\mathrm{n}\end{array}$} & 1981-2007 & 1.000 & 0.988 & 0.988 & 1.000 & 0.998 & 0.999 & 0.997 & -0.009 \\
\hline & & 1981-1989 & 1.000 & 0.967 & 0.967 & 1.000 & 0.966 & 1.000 & 0.966 & 0.001 \\
\hline & & 1990-1999 & 1.000 & 1.007 & 1.007 & 1.000 & 1.026 & 1.000 & 1.026 & -0.018 \\
\hline & & 2000-2007 & 1.000 & 0.984 & 0.984 & 1.000 & 0.997 & 0.996 & 0.993 & -0.009 \\
\hline & \multirow{4}{*}{ Machinery } & 1981-2007 & 1.026 & 1.007 & 1.034 & 1.001 & 1.018 & 1.001 & 1.020 & 0.014 \\
\hline & & 1981-1989 & 1.013 & 0.983 & 0.996 & 1.004 & 0.984 & 1.004 & 0.992 & 0.004 \\
\hline & & 1990-1999 & 1.050 & 1.003 & 1.053 & 1.000 & 1.056 & 0.989 & 1.045 & 0.008 \\
\hline & & 2000-2007 & 1.010 & 1.037 & 1.048 & 1.000 & 1.004 & 1.013 & 1.018 & 0.030 \\
\hline & \multirow{4}{*}{$\begin{array}{l}\text { Textile and } \\
\text { leather }\end{array}$} & 1981-2007 & 0.997 & 0.993 & 0.991 & 1.000 & 1.000 & 0.993 & 0.993 & -0.003 \\
\hline & & 1981-1989 & 1.012 & 1.004 & 1.016 & 1.000 & 0.993 & 0.983 & 0.975 & 0.040 \\
\hline & & 1990-1999 & 0.972 & 1.019 & 0.991 & 1.000 & 1.006 & 0.985 & 0.991 & 0.000 \\
\hline & & 2000-2007 & 1.011 & 1.005 & 1.016 & 1.000 & 1.000 & 1.015 & 1.015 & 0.001 \\
\hline & \multirow{4}{*}{$\begin{array}{l}\text { Wood and } \\
\text { wood } \\
\text { products }\end{array}$} & 1981-2007 & 0.992 & 0.982 & 0.974 & 0.978 & 1.000 & 1.010 & 0.988 & -0.014 \\
\hline & & 1981-1989 & 1.010 & 0.951 & 0.961 & 1.000 & 0.951 & 1.027 & 0.977 & -0.017 \\
\hline & & 1990-1999 & 0.990 & 0.988 & 0.978 & 1.000 & 0.990 & 1.002 & 0.991 & -0.014 \\
\hline & & 2000-2007 & 0.977 & 1.005 & 0.983 & 0.930 & 1.064 & 1.005 & 0.994 & -0.011 \\
\hline \multirow{16}{*}{ C } & \multirow{4}{*}{ Agriculture } & 1981-2007 & 1.002 & 0.996 & 0.998 & 1.000 & 0.999 & 1.000 & 1.000 & -0.002 \\
\hline & & 1981-1989 & 1.006 & 0.973 & 0.978 & 1.000 & 0.989 & 1.001 & 0.990 & -0.012 \\
\hline & & 1990-1999 & 0.964 & 0.977 & 0.941 & 1.000 & 1.009 & 1.000 & 1.009 & -0.067 \\
\hline & & 2000-2007 & 0.974 & 1.004 & 0.978 & 1.000 & 0.999 & 0.999 & 0.998 & -0.019 \\
\hline & & 1981-2007 & 0.997 & 0.993 & 0.990 & 1.000 & 1.000 & 0.998 & 0.998 & -0.008 \\
\hline & Food and & 1981-1989 & 1.000 & 1.007 & 1.007 & 1.000 & 0.994 & 0.993 & 0.987 & 0.021 \\
\hline & Tabaco & 1990-1999 & 0.950 & 1.037 & 0.985 & 1.000 & 1.005 & 1.006 & 1.011 & -0.026 \\
\hline & & 2000-2007 & 1.000 & 0.982 & 0.982 & 1.000 & 1.015 & 1.011 & 1.026 & -0.044 \\
\hline & & 1981-2007 & 1.000 & 0.989 & 0.988 & 1.000 & 0.988 & 0.999 & 0.986 & 0.002 \\
\hline & Iron and & 1981-1989 & 1.000 & 1.007 & 1.007 & 1.000 & 0.959 & 0.998 & 0.957 & 0.049 \\
\hline & steel & 1990-1999 & 1.008 & 0.970 & 0.978 & 1.000 & 1.015 & 0.994 & 1.009 & -0.031 \\
\hline & & 2000-2007 & 1.000 & 1.002 & 1.002 & 1.000 & 0.971 & 1.006 & 0.977 & 0.024 \\
\hline & & 1981-2007 & 0.977 & 0.986 & 0.964 & 0.982 & 1.000 & 1.010 & 0.992 & -0.028 \\
\hline & & 1981-1989 & 1.023 & 0.951 & 0.973 & 1.000 & 0.949 & 1.031 & 0.979 & -0.006 \\
\hline & and printing & 1990-1999 & 1.014 & 0.991 & 1.005 & 0.952 & 1.039 & 1.006 & 0.995 & 0.010 \\
\hline & & 2000-2007 & 0.991 & 0.994 & 0.984 & 1.002 & 1.002 & 0.980 & 0.983 & 0.001 \\
\hline & & "1981-2007 & "1.018 & 0.986 & "1.003 & 1.000 & 0.993 & 1.008 & "1.001 & 0.002 \\
\hline & Non- & 1981-1989 & 1.025 & 0.963 & 0.987 & 1.000 & 0.937 & 1.067 & 1.000 & -0.013 \\
\hline & $\begin{array}{l}\text { metallic } \\
\text { minerals }\end{array}$ & 1990-1999 & 1.088 & 0.944 & 1.027 & 1.000 & 1.021 & 0.979 & 1.000 & 0.027 \\
\hline & & $2000-2007$ & 0.997 & 0.964 & 0.961 & 1.000 & 1.016 & 0.988 & 1.003 & -0.042 \\
\hline $\mathbf{D}$ & & 1981-2007 & 1.004 & 0.987 & 0.991 & 1.000 & 1.003 & 0.993 & 0.996 & -0.005 \\
\hline V & Non- & 1981-1989 & 1.017 & 0.990 & 1.007 & 1.000 & 1.009 & 1.003 & 1.011 & -0.005 \\
\hline & $\begin{array}{l}\text { specified } \\
\text { industry }\end{array}$ & 1990-1999 & 0.966 & 0.996 & 0.962 & 1.000 & 1.002 & 0.987 & 0.989 & -0.027 \\
\hline & & 2000-2007 & 0.987 & 1.007 & 0.995 & 1.000 & 0.997 & 0.992 & 0.989 & 0.006 \\
\hline & Transport & 1981-2007 & 1.012 & 1.010 & 1.022 & 1.000 & 1.000 & 1.000 & 1.000 & 0.022 \\
\hline
\end{tabular}




\begin{tabular}{lllllllll}
$1981-1989$ & 1.009 & 0.966 & 0.974 & 1.000 & 0.994 & 1.006 & 1.000 & -0.026 \\
$1990-1999$ & 1.008 & 1.006 & 1.014 & 1.000 & 0.981 & 1.020 & 1.000 & 0.014 \\
$2000-2007$ & 1.020 & 1.063 & 1.084 & 1.000 & 1.031 & 0.970 & 1.000 & 0.083 \\
\hline
\end{tabular}

Note: Efficiency change (EC), technical change (TC), productivity change (PC), best practice gap change (BPC), and technology growth ratio change (TGC). $\triangle P C=P C_{-} M L-P C \_M M L$

APPENDIX B. ML and MML indices results and their decomposition by industry groups and time periods $^{26}$

\begin{tabular}{cccccccccc}
\hline \multirow{2}{*}{ GROUP } & PERIOD & \multicolumn{3}{c}{ ML index } & \multicolumn{7}{c}{ MML index } & \multirow{2}{*}{$\Delta$ PC } \\
\cline { 3 - 8 } & & EC & TC & PC & EC & BPC & TGC & PC & \\
\hline \hline \multirow{4}{*}{ A } & $1981-2007$ & 1.0123 & 0.9877 & 1.0000 & 1.0000 & 0.9983 & 1.0043 & 1.0027 & -0.0027 \\
& $1981-1989$ & 1.0077 & 0.9860 & 0.9933 & 1.0000 & 0.9943 & 1.0183 & 1.0127 & -0.0193 \\
& $1990-1999$ & 1.0310 & 0.9900 & 1.0207 & 1.0000 & 1.0027 & 1.0007 & 1.0033 & 0.0173 \\
& $2000-2007$ & 0.9943 & 0.9867 & 0.9810 & 1.0000 & 0.9970 & 0.9947 & 0.9917 & -0.0107 \\
\hline \multirow{3}{*}{ B } & $1981-2007$ & 1.0038 & 0.9925 & 0.9968 & 0.9948 & 1.0040 & 1.0008 & 0.9995 & -0.0027 \\
& $1981-1989$ & 1.0088 & 0.9763 & 0.9850 & 1.0010 & 0.9735 & 1.0035 & 0.9775 & 0.0075 \\
& $1990-1999$ & 1.0030 & 1.0043 & 1.0073 & 1.0000 & 1.0195 & 0.9940 & 1.0133 & -0.0060 \\
& $2000-2007$ & 0.9995 & 1.0078 & 1.0078 & 0.9825 & 1.0163 & 1.0073 & 1.0050 & 0.0028 \\
\hline \multirow{3}{*}{ C } & $1981-2007$ & 0.9940 & 0.9910 & 0.9850 & 0.9955 & 0.9968 & 1.0018 & 0.9940 & -0.0090 \\
& $1981-1989$ & 1.0073 & 0.9845 & 0.9913 & 1.0000 & 0.9728 & 1.0058 & 0.9783 & 0.0130 \\
& $1990-1999$ & 0.9840 & 0.9938 & 0.9773 & 0.9880 & 1.0170 & 1.0015 & 1.0060 & -0.0287 \\
& $2000-2007$ & 0.9913 & 0.9955 & 0.9865 & 1.0005 & 0.9968 & 0.9990 & 0.9960 & -0.0095 \\
\hline \multirow{2}{*}{ D } & $1981-2007$ & 1.0113 & 0.9943 & 1.0053 & 1.0000 & 0.9987 & 1.0003 & 0.9990 & 0.0063 \\
& $1981-1989$ & 1.0170 & 0.9730 & 0.9893 & 1.0000 & 0.9800 & 1.0253 & 1.0037 & -0.0143 \\
& $1990-1999$ & 1.0207 & 0.9820 & 1.0010 & 1.0000 & 1.0013 & 0.9953 & 0.9963 & 0.0047 \\
& $2000-2007$ & 1.0013 & 1.0113 & 1.0133 & 1.0000 & 1.0147 & 0.9833 & 0.9973 & 0.0160 \\
\hline
\end{tabular}

Note: Efficiency change (EC), technical change (TC), productivity change (PC), best practice gap change (BPC), and technology growth ratio change (TGC). $\triangle P C=P C_{-} M L-P C \_M M L$

26 Table 6, Appendix A and B are based on same value, but rounding off and different decimal cause small difference in the mean values. However, the difference has no negative implications for the results and its analysis. 